\title{
Understanding the gleason grading system and its changes
}

\author{
Sujata Pudasaini ${ }^{1}$, Neeraj Subedi ${ }^{2}$ \\ ${ }^{1}$ Department of Pathology, Nepal Medical College Teaching Hospital, Kathmandu, Nepal \\ ${ }^{2}$ Department of Urology, Nepal Medical College Teaching Hospital, Kathmandu, Nepal
}

\author{
Keywords: \\ Carcinoma; \\ Gleason grade; \\ International Society of \\ Urological Pathology; \\ Prostate
}

\begin{abstract}
Gleason Grading System is the most widely used grading system used for prostatic carcinoma. The five basic grade patterns are used to generate a histologic score, which can range from 2 to 10 (including primary and secondary patterns). The original Gleason Grading System was used to grade acinar adenocarcinoma based on architectural features and it has been correlated with excellent clinical outcomes. Since 1960s, after the discovery of the original Gleason Grading System, a modified version of the Gleason Grading System was introduced in the International Society of Urological Pathology 2005 which came up with many changes including elimination of Gleason pattern 1. The ISUP 2005 was further updated in 2014 to provide more accurate stratification of prostatic carcinoma. The new Gleason Grade Group 1 to 5 has been introduced and it has little resemblance to the original Gleason system. This Gleason Grade Group has been accepted by the 2016 World Health Organization classification of tumors of the prostate.

For a needle biopsy, high grade component of any quantity should be included in the Gleason score as it indicates a high probability of finding significant high grade tumor in the prostate. By understanding the principles and practice of this grading system, the pathology report has to clearly indicate which system is adopted in the reporting. This review discusses GGS and its recent development focusing on major changes over the years that led to the new Grade Group system proposed by the 2014 ISUP consensus.
\end{abstract}

\section{Correspondence:}

Dr. Sujata Pudasaini, MD

Associate Professor, Department of Pathology,

Nepal Medical College Teaching Hospital, Kathmandu, Nepal

ORCID ID: 0000-0001-9699-8204

Email:sujatapudasaini@gmail.com

Reveived : August $14^{\text {th }} 2019$; Accepted : September $22^{\text {nd }} 2019$

Citation: Pudasaini S, Subedi N. Understanding the Gleason Grading System and its changes. J Pathol Nep 2019;9:1580-5.DOI 10.3126/jpn.v9i2.25723

Copyright: This is an open-access article distributed under the terms of the Creative Commons Attribution 4.0 International License, which permits unrestricted use, distribution, and reproduction in any medium, provided the original author and source are credited.

\section{INTRODUCTION}

Grading is defined as a step in a process and histological grade of any neoplastic process is considered the same as the degree of differentiation of the neoplastic cells. ${ }^{1}$ Gleason Grading System (GGS) is the most widely used system for prostatic adenocarcinoma. ${ }^{1-5}$ It is one of the most useful predictors of prognosis of prostatic carcinoma. ${ }^{2-4}$ The original GGS was used to grade acinar adenocarcinomas based on architectural features and it has an excellent correlation with clinical outcomes. ${ }^{1,3}$ The grading system uses a 5 point scale where 1 corresponds to well differentiated tumor and 5, the poorly differentiated. ${ }^{6,7}$ The International Society of Urological Pathology (ISUP) introduced major modifications to the Gleason system in 2005., , $^{2}$ There were a 
Table 1: Gleason Grade group by corresponding Gleason score 14

\begin{tabular}{|c|c|c|}
\hline Grade group & Gleason Score & Definition \\
\hline 1 & $6(3+3)$ & Only individual, discrete, well-formed glands \\
\hline 2 & $7(3+4)$ & $\begin{array}{l}\text { Predominantly well-formed glands with a lesser component of poorly formed/ fused/cribriform/ } \\
\text { glomeruloid glands }\end{array}$ \\
\hline 3 & $7(4+3)$ & $\begin{array}{l}\text { Predominantly poorly formed/fused/ cribriform/glomeruloid glands with a lesser component of } \\
\text { well-formed glands }\end{array}$ \\
\hline 4 & $8(4+4,3+5,5+3)$ & $\begin{array}{l}\text { Only poorly formed/fused/cribriform/glomeruloid glands or } \\
\text { Predominantly well-formed glands and lesser component lacking glands or } \\
\text { Predominantly lacking glands with a lesser component of well-formed glands }\end{array}$ \\
\hline 5 & $\begin{array}{l}9,10(4+5,5+4 \\
5+5)\end{array}$ & $\begin{array}{l}\text { Lack of gland formation (or with necrosis) with or without poorly } \\
\text { formed/fused/cribriform glands }\end{array}$ \\
\hline
\end{tabular}

few modifications in the year 2010 ISUP on GGS2 followed by some controversies in $2014 .{ }^{4}$

The GGS closely correlates with clinical behaviour and provides an important index of prognosis. ${ }^{8}$ The Gleason score is one of the key determinants in treatment decision making, together with stage, age, and prostate-specific antigen. $1,4,7,8$

\section{ORIGIN OF GLEASON GRADING SYSTEM}

A unique grading system for prostate carcinoma was first introduced in 1966 by Donald F. Gleason. ${ }^{6,910}$ It was based on the low power architectural pattern of the tumor, using a 5-point scale, where patterns 1,2 and 3 represented tumors that most closely resembled normal prostatic glands and patterns 4 and 5 were tumors showing increasingly abnormal glandular architecture. ${ }^{6,11}$ This system was based on a study of 270 patients. Later in 1974 and 1977, the study was expanded to include a number of patients and there were further refinements to the system. ${ }^{6,10}$

The GGS was further defined as the sum of the two most common patterns and was reported as the Gleason score. ${ }^{1,6,9,10,12,13}$ When two patterns were combined to give the Gleason score, the worst grade was assigned as an average grade comprising the most prevalent and the second most prevalent pattern. Hence, the Gleason score was the combination of primary and secondary patterns to generate the score ranging from 2 to $10 .^{1,10,12,13}$ The sum of the primary (eg. Gleason- 3) and secondary (eg. Gleason4) patterns yielded Gleason score of 7. In cases, with just one pattern (eg. Gleason -3), the primary and secondary patterns were considered the same and the Gleason score of $3+3=6$ was obtained. This Gleason scores correlated with the biological behaviour of prostate adenocarcinoma even better. ${ }^{11}$ In 1977, Gleason emphasized that the grading is performed under the low magnification. He also stated that neither an occasional small area of fused glands can change a pattern 3 tumor to pattern 4 nor a small focus of disorganized cells can change a pattern 3 or 4 tumors to pattern $5 .{ }^{6}$ Occasional small areas of third pattern (tertiary pattern) in some prostatic carcinoma was also considered in the year $1977 .{ }^{13}$

The WHO endorsed the Gleason grading system in the 2004 classification of prostate cancer, which has also been incorporated into the AJCC (American Joint Committee on Cancer)/ UICC (Union for International Cancer Control) staging system, as well as the NCCN (National Comprehensive Cancer Network) guidelines as one of the key factors along with serum prostate specific antigen (PSA) and staging in the treatment decision. ${ }^{12}$ Of the many proposed systems over time for the grading of prostate cancer, currently the most widely accepted and used is the GGS. ${ }^{10,12}$

\section{CLASSICAL GLEASON GRADING}

The GGS is based entirely on the histologic pattern of arrangement of carcinoma cells at low power. In the original system, Gleason pattern 1 is characterized by a well-circumscribed, nodular lesion composed of roughly uniform, closely compacted, well-differentiated glands of moderate size. ${ }^{12}$ This pattern is very rare and may be mimicking lesions such as adenosis. ${ }^{1,9,12}$ Pattern 1 carcinoma is most often an incidental finding in transition zone tissue diagnosed in Transurethral retrograde prostatectomy (TURP) chips in the case of Benign prostatic hyperplasia $(\mathrm{BPH})$ or in radical prostatectomy (RP) specimen where peripheral involvement is there with intermediate to high grade carcinoma. ${ }^{1}$ In contrast, Gleason pattern 2 may show variations in sizes of the neoplastic glands, slightly increased stroma between the glands and even slight irregularity at the periphery of the nodule. This pattern is also considered to be very rare. ${ }^{11}$ With the current changes in the Gleason grading, all the previously considered Gleason pattern 2 adenocarcinomas are now classified as Gleason grade $3 .{ }^{9}$

Gleason pattern 3, the most common pattern, is comprised of individual, discrete and distinct neoplastic glands, typically small, but often of variable sizes and infiltrating into the stroma in between the benign glands and should be diagnosed at low magnification. It also includes cribriform 
structures or "gland in gland formation", i.e., glomerulation, which have been recently moved into pattern $4 .{ }^{9,12}$ Gleason pattern 4 comprises of fused glands resulting in broad, irregular fused glandular or cribriform patterns. Comedo type necrosis, solid or cordlike growth or infiltration by individual tumor cells upgrades to pattern 5.,12 Indraductal carcinoma can mimic Gleason pattern 5 and hence frequently undergraded. ${ }^{9}$

\section{TRENDS IN THE PRACTICE OF GLEASON GRADING}

Diagnosis and management of prostatic carcinoma have changed dramatically since the late 1960 s. ${ }^{6,10}$ In the Gleason 1974 study, most men had advanced disease with either local or distant metastases. The method of obtaining prostate tissue was also different from today's practice. The extensive sampling technique was not developed until the 1980s. ${ }^{6}$ With the widespread use of PSA screening, there has been a remarkable shift in disease staging towards the low-stage prostate cancers. Extended and saturation biopsy templates are used instead of limited, targeted biopsies to improve prostate cancer detection. The practice of grading of prostatic carcinoma in multiple cores submitted from separate sites is introduced too. ${ }^{10,13}$

The grading of prostate cancer in thin cores and in multiple cores from different sites of the prostate was not the issue in the Gleason era. Issues relating to radical prostatectomy specimens, such as the grading of multiple nodules within the same prostate, determining variants and variations of carcinoma, or dealing with tertiary patterns, were not addressed within the original Gleason system. ${ }^{6}$ The lowest Gleason pattern 1 and 2 is now almost completely abandoned. Also, the concept of atypical cribriform lesions and adenosis has improved with the widespread use of immunohistochemistry. ${ }^{6,10,14}$ The vital changes which occurred over the last few decades had led to enhanced understanding, refinements and rearrangement of the Gleason patterns and the better outcome. ${ }^{14}$ The GGS still remains one of the most powerful prognostic factors in prostatic carcinoma. ${ }^{6}$

\section{THE MODIFIED GLEASON GRADING SYSTEM (BASED ON 2005 ISUP)}

Conference in 2005 in San Antonia, Texas led to the 2005 ISUP Modified Gleason System. The Gleason score is the sum of the primary (most predominant) Gleason grade and the secondary (second most predominant) Gleason grade. ${ }^{6,12,15}$ One of the most prominent changes in the consensus is that Gleason score $1+1=2$ should not be diagnosed, despite the allocation for very rare exceptions. It has also been recognized that diagnosing Gleason 1 on needle biopsies is not acceptable since a "Gleason 1" nodule cannot be assessed by a core biopsy. Even with TURP or RP samples, the original Gleason scores $1+1=2$ nodules mostly are adenosis by modern standards. This basically eliminates Gleason 1 pattern. ${ }^{6,12-14}$

Gleason score 3 or 4 on needle biopsies (comprising of grades $1+2,2+1$ and 2+2) has also been controversial. The ISUP consensus recommended that diagnosis of Gleason score 3 or 4 can be made rarely on needle biopsies from transition zone or apex and after consultation with experts. ${ }^{12}$ The original Gleason pattern 3 which included distinct glands of variable sizes to cribriform growths pattern and individual cells has been changed. The individual cells of Gleason pattern 3 were removed and large cribriform growths were moved to pattern 4 , but still allowed diagnosis of cribriform pattern 3 in well-circumscribed, smooth and rounded normal sized glands. ${ }^{12,13,16-18}$ Later, small cribriform and glomeruloid glands have been reconsidered as Gleason grade 4.With this there is a relative decrease in Gleason score 6 and an increase in Gleason score 7. ${ }^{16,17}$

In Gleason pattern 4, there should be ill-defined glands with poorly formed glandular lumina. Comedo necrosis in solid nests or cribriform background formations was considered as Gleason pattern 5, and it was emphasized that stringent criteria should be applied for comedo necrosis, which included intraluminal necrotic cells and karyorrhexis., ${ }^{9} 12$ When modified GGS was used, the Gleason score 3+4=7 tumor has a very favourable prognosis compared to Gleason score $4+3=7$ for both needle biopsy and RP specimen. Hence it is worth separating Gleason score 7 into two prognostic groups. It was also seen that Gleason score $4+3=7$ behaves more similarly to a tumor with Gleason score $8{ }^{13,19,20}$ Further it was concluded that the vacuoles, foamy cytoplasm and mucinous extra vasation should be ignored. Pseudo hyperplastic adeno carcinoma was graded as Gleason score $3+3=6$ and ductal adeno carcinoma as Gleason score $4+4=8 .{ }^{12}$

Modified Gleason system 2005 and later developments basically eliminated Gleason grade 1, and put very stringent limits on Gleason pattern 2. ${ }^{12,18}$ The diagnosis of Gleason pattern 1 and 2 were not to be made in the biopsy specimen. ${ }^{21}$ Gleason 3 would thus be the lowest grade assigned if no higher grade patterns were identified. Many changes were made to Gleason pattern 3, particularly the moving of most original Gleason pattern 3 cribriform structures as well as clusters of poorly formed glands into Gleason $4 .^{12,18,22}$

These modifications when applied to needle biopsy seem to be more complicated than previous versions. In the setting of high grade carcinoma on needle biopsy, if there was low grade cancer on the same core occupying less than $5 \%$ of cancer, the low grade cancer was not included in the Gleason score. ${ }^{19,21}$ But in the same needle biopsy, the primary pattern and worst ( not secondary) pattern were recommended to be included in the needle biopsy. ${ }^{21}$ The 2005 modified GGS 
also decided that each core in needle biopsies should be given an individual Gleason score and recommended that cores be taken from different areas of prostate and sent in separate containers. ${ }^{9,13}$

\section{CHANGES AFTER 2014 ISUP}

Update in the grading of prostate cancer of 2005 was made after the meet in November 2014 in Chicago by 65 prostate cancer pathology experts from 19 different countries. ${ }^{13,21}$ The 2014 ISUP Gleason score and GGS were introduced to overcome the 2005 Gleason score pitfalls. ${ }^{14,21,23-25}$

There were few major conclusions made out of 2014 ISUP. Cribriform and glomeruloid glands (regardless of morphology) should be assigned a Gleason pattern 4 . Grading of mucinous carcinoma of the prostate should be based on its underlying growth pattern rather than grading them all as pattern 4. Similarly, intraductal carcinoma without invasion should not be assigned a Gleason grade but a comment needs to be added as there could be an invariable association with aggressive prostate cancer. ${ }^{21,26}$

There was a clear consensus on Gleason pattern 4 which includes cribriform, fused, and poorly formed glands. The term hypernephromatoid cancer should not be used. Also occasional poorly formed or fused glands between wellformed glands are insufficient for a diagnosis of pattern 4 . In cases with borderline morphology between Gleason pattern 3 and pattern 4 and crush artifacts, the lower grade should be favoured. Solid medium to large nests with rosette-like spaces and the presence of unequivocal comedonecrosis, even if the focal represents Gleason pattern $5 .{ }^{21}$

The Gleason grading system ranges from 2 to 10 , yet 6 is the lowest score currently assigned (Table 1).14 This new system was validated in a multi-institutional study of thousands of biopsy and radical prostatectomy specimens. ${ }^{21}$

The reporting of Gleason scores 2 to 5 has virtually disappeared from current clinical practice. ${ }^{14,21}$ This new grading system more accurately reflects prostate cancer biology than the Gleason system. Grade group1 out of 5 better characterizes the tumor than reporting as Gleason score 6 out of 10 and has an excellent prognosis. Grade group 2 also has a very good prognosis when compared to Grade group 3. Grade group 4 is not considered the highest in this grading system. However grade group 5 obviates the need to distinguish between Gleason scores $4+5,5+4$, and $5+5$ just as grade group $1(2+2,2+3,3+2$, and $3+3) .{ }^{21}$

The reason for the adoption of this Gleason Grading system is because it is simple and its grading category ranges grom Gleason scores 2 to 10 . The lowest grade is 1 , not 6 as in Gleason, with the potential to reduce overtreatment of indolent cancer. ${ }^{21,23-25,27}$
The recommendation from the 2014 meeting was the same as in the 2005 consesus for grading separate cores with different grades and assigning individual Gleason scores to separate cores as long as the cores were submitted in separate containers or the cores were in the same container yet specified by the urologist as to their location (ie by different color inks). One should also assign a grade to the non dominant nodule. ${ }^{21,24}$ Most of the participants at the Chicago grading meeting voted in support of adopting the new grading system. The new grading system and the terminology "Grade Groups 1-5" has also been accepted by the World Health Organization for the 2016 edition of Pathology and Genetics: Tumours of the Urinary System and Male Genital Organs. ${ }^{21,28}$

In needle biopsies, the risk of under grading biopsy Gleason scores 6 must be considered to choose the treatment modality as preoperative Gleason score is often upgraded after an RP. By increasing the amount of tissue in prostate biopsy is one way to avoid the undergrading. ${ }^{9,29}$ Pathologists should report the grades of each core separately when submitted in separate containers. ${ }^{9}$ Discordance between the Gleason score on needle biopsy and the core of the RP specimen is common and universal. Though the moderate group was the most difficult to diagnose in needle biopsy, the overall reliability of Gleason grading of needle biopsies in predicting the final pathology was found to be satisfactory. ${ }^{30}$

In needle core biopsies, both the most common and highest grade are added to get the Gleason score. Any amount of high grade tumor sample on needle biopsy most likely indicates a high grade tumor within the prostate. ${ }^{9}$

\section{CONCLUSIONS}

After more than four decades, the GGS still remains the most widely accepted grading system in the evaluation of prostatic adenocarcinoma. However, the pathology report should mention the system which is adopted in the reporting of each case and definitely with the application of WHO 2016 and Gleason Grade group, there is upgradation in the prognosis of prostatic carcinoma.

\section{Conflict of Interest: None}

\section{REFERENCES}

1. Humphrey PA. Gleason grading and prognostic factors in carcinoma of the prostate. Modern Pathol. 2004; 17: 292-306. Crossref

2. Kayipmaz SS. New assessment of Gleason grading system in prostatic adenocarcinoma. J Urol Surg. 2016;1:36-7. Crossref

3. Sehn JK. Prostate Cancer Pathology: Recent Updates and controversies. Missouri Med. 2018; 115: 151-5 
4. Rao V, Garudadr G, Shilpa AS et al. Validation of the WHO 2016 new Gleason score of prostatic carcinoma. Urol Ann. 2018; 10: 3249. $\underline{\text { Crossref }}$

5. Rapiti E, Schaffar R, Iselin C et al. Importance and determinants of Gleason score undergrading on biopsy sample of prostate cancer in a population-based study. Bio Med Central Urol. 2013; 13: 19. $\underline{\text { Crossref }}$

6. Egevad L, Mazzucchelli R, Montironi R. Implications of the International Society of Urological Pathology Modified Gleason grading system. Arch Pathol Lab Med. 2012; 136: 426-34. Crossref

7. True L, Coleman I, Hawley S et al. A molecular correlate to the Gleason grading system for prostate adenocarcinoma. Proc Natl Acad Sci USA. 2006; 103: 10991-6 $\underline{\text { Crossref }}$

8. Sarici H, Telli O, Yigitbasi O et al. Predictors of Gleason score upgrading in patients with prostate biopsy Gleason score $\leq 6$. Can Urol Assoc J. 2014; 8: 342-6.

9. Gordetsky J, Epstein J. Grading of prostatic adenocarcinoma: current state and prognostic implications. Daign Pathol. 2016; 11: 25. Crossref

10. Shah RB. Current perspectives on the Gleason grading of prostate cancer. Arch Pathol Lab Med. 2009; 133:1810-6

11. Arora R, Koch MO, Eble JN, Ulbright TM, Li L, Cheng L. Heterogeneity of Gleason grade in multifocal adenocarcinoma of the prostate. Cancer. 2004; 100: 2362-6. Crossref

12. Chen N, Zhou Q. The evolving Gleason grading system. Chin J Cancer Res. 2016; 28: 58-64

13. Barakzai MA. Prostatic adenocarcinoma: a grading from Gleason to the new Grade-Group system: a historical and critical review. Asian Pac J Cancer Prev. 2019; 20: 661-6. Crossref

14. Paner GP, Gandhi J, Choy B, Amin MB. Essential updates in grading, morphotyping, reporting and staging of prostate carcinoma for general surgical pathologists. Arch Pathol Lab Med. 2019; 143: 55064. Crossref

15. Montironi R, Mazzuccheli R, Scarpelli M, Lopez $\square$ Beltran A, Fellegara G, Algaba F. Gleason grading of prostate cancer in needle biopsies or radical prostatectomy specimens: contemporary approach, current clinical significance and sources of pathology discrepancies. Br J Urol Intl. 2005; 95:1146-52. Crossref

16. Pierorazio PM, Walsh PC, Partin AW, Epstein JI. Prognostic Gleason grade grouping: data based on the modified Gleason scoring system. Br J Urol Intl. 2013; 111: 753-60. Crossref

17. Kweldam CF, Wildhagen MF, Steyerberg EW, Bangma CH, Kwast TH van der, Leenders G JLH van. Cribriform growth is highly predictive for postoperative metastasis and disease specific death in
Gleason score 7 prostate cancer. Modern Pathol. 2015; 28: 457-64. $\underline{\text { Crossref }}$

18. Priyadarsini R, Saju PR, Nambiar AR, Sadasivan S. Carcinoma prostate histopathology in needle biopsies including revised Gleason's grading and role of immunohistochemical markers. J Evid Based Med Health. 2017; 4: 2443-6. Crossref

19. Kryvenko ON, Epstein JI. Prostate cancer Grading: a decade after the 2005 Modified Gleason Grading System. Arch Pathol Lab Med. 2016; 140: 1140-52. Crossref

20. McKenney JK, Wei W, Hawley S et al. Histologic Grading of prostatic adenocarcinoma can be further optimized: analysis of the relative prognostic strength of individual architectural patterns in 1275 patients from the Canary retrospective cohort. Am J Surg Pathol. 2016; 40:1439-56. $\underline{\text { Crossref }}$

21. Epstein JI, Egevad L, Amin MB, Delahunt B, Srigley JR, Humphrey PA. The 2014 International Society of Urological Pathology (ISUP) consensus conference on Gleason Grading of prostatic carcinoma: definition of Grading patterns and proposal for a new Grading system. Am J Surg Pathol. 2016; 40: 244-52. $\underline{\text { Crossref }}$

22. Thomsen FB, Folkvaljon Y, Brasso K et al. Prognostic implications of 2005 Gleason grade modification. Population- based study of biochemical recurrence following radical prostatectomy. J Surg Oncol. 2016; 114:664-70 Crossref

23. Kristiansen G, Egevad L, Amin M. The 2014 consesus conference of the ISUP on Gleason grading of prostatic carcinoma. Pathologe. 2016; 37: 17-26 $\underline{\text { Crossref }}$

24. Epstein JI, Amin MB, Reuter VE, Humphrey PA. Contemporary Gleason Grading of prostatic carcinoma: an update with discussion on practical issues to implement the 2014 International Society of Urological Pathology (ISUP) consesus conference on Gleason Grading of prostatic carcinoma. Am J Surg Pathol. 2017; 41: 1-7 Crossref

25. Shah MB, Raju K, Kumar HG. Revisiting prostate biopsy with 2014 ISUP modified Gleason Score and Gleason Grade- a cross section study. Biomed Res Ther. 2018; 5: 2918-25. Crossref

26. Srigley JR, Delahunt B, Samaratunga $\mathrm{H}$ et al. Controversial issues in Gleason and International Society of Urological Pathology (ISUP) prostate cancer grading: proposed recommendations for international implementation. Pathology. 2019; 51: 463-73 $\underline{\text { Crossref }}$

27. Epstein JI, Zelefsky MJ, Sjoberg DD et al. A contemporary prostate cancer grading system: a validated alternative to the Gleason Score. Eur Urol. 2016; 69: 428-35 $\underline{\text { Crossref }}$

28. Yeldir N, Yildiz E, Dundar G. Gleason scvore correlation between prostate needle biopsy and radical prostatectomy materials. Turk Patoloji Derg. 2019; 35: 185-92 $\underline{\text { Crossref }}$ 
29. Cicione A, Cantiello F, Damiano R. Needle biopsy size and pathological Gleason score diagnosis: No evidence for a link. Can Urol Assoc J. 2013; 7: 567-71 Crossref
30. Khoddami M, Khademi Y, Aghdam MK, Soltanghoraee H. Correlation between Gleason score in needle biopsy and corresponding radical prostatectomy specimens: a twelve year review. Iran J Pathol. 2016; 11: $120-6$ 